1. Alperstein G. Lead - where are we now and where to from here? NSW Public Health Bulletin 1995; 6:119-121.

2. Aldrich R, Toneguzzi R, Wlodarczyk J, Hensley MJ. Assessing the impact of a new motorway on children's blood lead levels. NSW Public Health Bulletin 1995; 6:121-123.

3. Coe A, Beil G, Neck M. The OECD risk reduction strategy for lead an economic perspective. Aust Bureau Agric Res Econ Res Rep 1994; 14:28-40.

4. Elwood PC, Gallacher JEJ. Lead in petrol and levels of lead in blood; scientific evidence and social policy. J. Epidemiol Community Health. $1984 ; 38: 315-318$.

5. Guidance manual for the integrated exposure uptake biokinetic model for lead in children. EPA/540/R-93/081. Washington, DC: United States

Environmental Protection Agency, 1994; 4.10-4.16

6. NSW Interdepartmental Lead Taskforce. Report of NSW lead management action plan. Sydney. Sydney: NSW Environmental Protection Agency, 1994.

7. Pirkle JL, Brody DJ, Gunter EW, et al. The decline in blood lead levels in the United States; the National Health and Nutrition Surveys. JAMA 1994; 272:284-291.

8. UK Blood Lead Monitoring Programme 1984-1987. Results for 1987.

Pollution report no. 28. London: Her Majesty's Stationery Office, 1990

9. Donovan J, Anderson P, Daley C, Lea T, et al. Lead in Australian children: report on the national survey of lead in children. Canberra: Australian Institute of Health and Welfare, 1996.

10. von Schirnding Y, Bradshaw D, Fuggle R, Stokol M. Blood lead levels in South Africa inner city children. Environ Health Perspect 1991; 94:125-130.

11. Deane M. Report on study of blood lead concentrations in Culver City school children. State of California, Department of Health. Report to the Board of Education, 1977.

12. Revision of the Australian guidelines for lead in blood and lead in ambient air. Report of 115 th session. Canberra: National Health and

Medical Research Council, 1993.

13. Mira M, Bawden-Smith J, Causer J, Alperstein G, et al. Blood lead concentrations of pre school children in Central and Southern Sydney Med J Aust 1996; 164:399-402

14. Edwards-Bert P, Calder IC, Maynard EJ. National review of public exposure to lead in Australia. Adelaide: South Australian Health Commission, 1993.

15. Gulson BL. Paint as a source of recontamination of houses in urban environments and its role in maintaining elevated blood lead levels in children. Sci Total Environ 1995; 164:221-235.

16. Donovan J. No lead is good lead [editorial]. Med J Aust 1996; 164:390-391.

Response from Dr Garth Alperstein, Central Sydney Area Health Service

Dr Bell makes two points:

- that lead-based paint as a source of lead exposure requires further attention

- that he believes, as does Dr Donovan, that alleviating social disadvantage may in the long term be more beneficial than action directed specifically at exposure to lead.

I do not believe anyone would disagree on either issue Alleviating social disadvantage is a complex and difficult long-term issue and will positively affect more than just those problems associated with lead exposure. In the meantime, there are simple measures that can be implemented to reduce children's exposure to lead. How much effort, money and human resources are put into dealing with all health issues, including lead, are what governments and the community are constantly negotiating.

\section{UPDATE ON LEAD-RELATED ACTIVITIES, FROM THE PUBLIC HEALTH UNITS}

\section{CENTRAL SYDNEY AREA PUBLIC HEALTH UNIT}

Central Sydney Public Health Unit convenes quarterly meetings of the multidisciplinary Lead Advisory Committee. The committee has representation from the Central Sydney Public Health and Health Promotion Units, local Divisions of General Practice, the Lead Reference Centre, the Lead Advisory Service (NSW), the Department of Housing, and the paint industry, as well as the Central Sydney community paediatrician and a local council environmental health officer. The committee aims to reduce the effects on health of lead and the risks from lead within the Central Sydney Health Area by promoting and coordinating responses to lead within the Area, and liaising and collaborating with organisations outside the health sector. The committee also functions as a forum for information sharing about lead issues generally. In July 1997, a subcommittee was established to look at research issues. The Lead Research Sub-Committee aims to advise the Lead Advisory Committee and others about needs for research about lead, and to formulate research questions about lead issues.

A public health officer placed in the Central Sydney Public Health Unit undertook a literature review to examine evidence of the effectiveness of behavioural interventions aimed at health professionals, families and others to address lead issues.

The Central Sydney Area Public Health Unit developed a local protocol for the follow-up of notifications of people with elevated blood lead levels. This protocol was used to investigate cases of elevated blood lead levels in the Central Sydney Area before the NSW Health guideline for Environmental Health Officers became available. The protocol's public health unit operational summary, the letter to general practitioners about adult notifications, and the notification action checklist were used as examples in the NSW Health Department guideline.

\section{HUNTER AREA PUBLIC HEALTH UNIT}

In the North Lake Macquarie area, the Hunter Area Public Health Unit has been undertaking programs and research on lead issues:

- analysis of blood lead levels of children in the suburbs of North Lake Macquarie, and relevant comparisons

- ongoing evaluation of children's blood lead levels after household remediation

- a knowledge, attitudes and practices survey of parents whose homes have been remediated.

The North Lake Macquarie Remediation Centre was established at the end of 1995 with funding of $\$ 300,000$ from the NSW Government Environmental Trust, the NSW Health Department, Pasminco Metals Sulphide and Lake Macquarie City Council. In 1996, the Centre started remediation of houses around the Pasminco Cockle Creek smelter, where children had high blood lead levels. 


\section{Lead in dust and soil from day-care centres}

\section{Continued from page 95}

\section{ACKNOWLEDGMENTS}

We thank: Macquarie University for financial support for this study under the Macquarie University Research Grants Scheme; Ms Ginie Udy of the Uniting Church Children's Services Forum for access to the day-care centres; the coordinators of the centres for their assistance; Professor Barry Batts for access to the ICP-AES; and Graeme Waller for the surface wipe digestion method.

1. National Center for Lead Safe Housing, Maryland. Guidelines for the evaluation of lead-based paint hazards in housing. February 1995. 2. Bawden-Smith J, McAnulty J, Bek M. Lead exposure at a school for children with developmental disabilities. NSW Public Health Bulletin 1995; 6(11):124-6.

3. Fett MJ, Mira M, Smith J et al. Community prevalence survey of children's blood lead levels and environmental lead contamination in inner Sydney. Med J Aust 1992; 157:441-5.

4. Gulson BL, Jameson CW, Mahaffey KR, Mizon KJ, Korsch MJ, Vimpani G. Pregnancy increases mobilisation of lead from maternal skeleton. J Lab Clin Med 1997; 130:51-62.

5. National Research Council. Measuring lead exposure in infants, children, and other sensitive populations. Washington DC: National Academy Press, 1993.

6. Chiaradia M, Gulson BL, Mizon KJ, James M, Jameson CW, Johnson D. Identification of secondary lead sources in the air of an urban environment. Atmos Environ 1997; 31:3511-21.

7. NSW Government Lead Issues Paper. Sydney: Environment

Protection Authority, 1993.

8. Gulson BL, Davis JJ, Bawden-Smith J. Paint as a source of recontamination of houses in urban environments and its role in maintaining elevated blood leads in children. Sci Total Environ 1995 maintainin

164:221-35.
9. Gulson BL, Davis JJ, Mizon KJ, Korsch MJ, Bawden-Smith J. Sources of lead in soil and dust and the use of dust fallout as a sampling medium. Sci Total Environ 1995; 166:245-62.

\section{EDITORIAL NOTE}

Lead is a ubiquitous contaminant of the urban environment. Children are at greatest risk of exposure and harm from absorption of environmental lead by virtue of their behaviour, their metabolism and the sensitivity of the developing nervous system to the toxic effects of lead. Lead in paint and lead additives in fuel are two sources of lead exposure in urban areas. This study confirms that lead is readily detected in the home and play environment of many children in NSW. A recent study showed that average blood lead levels in NSW preschool children were 5 to $7 \mu \mathrm{g} / \mathrm{dL}$, with less than 25 per cent of inner-city children being above the goal for blood lead of $10 \mu \mathrm{g} / \mathrm{dL}^{1}$. This is an improvement since $1992^{2}$. Reductions in the proportion of cars using leaded fuel and in the the lead added to that fuel have reduced exposure. A study in Sydney showed that traffic flow near a child's home was a more important determinant of blood lead level than the traffic flow at the child's child-care centre ${ }^{3}$. These results do not detract from the need for efforts to reduce exposure to environmental lead, such as those now being coordinated by the Lead Reference Centre.

1. Mira M, Bawden-Smith J, Causer J, et al. Blood lead concentrations of preschool children in Central and Southern Sydney. Med J Aust 1996; 164:399-402.

2. Fett M, Mira M, Smith J, et al. Community prevalence survey of children's blood lead levels and environmental lead contamination in inner Sydney. Med J Aust 1992; 157:441-445.

3. Cowie C, Black D, Fraser I. Blood lead levels in preschool children in eastern Sydney. Aust NZ J Public Health 1997; 21:755-760.
Measuring the amount of lead in indoor dust

\section{Continued from page 93}

Thus, the petri dish method can be used as a measure of recontamination, allowing individuals and health authorities to assess the effectiveness of abatement strategies.

Although no single method has yet been established as a standard for measuring indoor lead exposure, the long-term dust-fall accumulation method has advantages: it has low cost, does not require a power source, causes minimal inconvenience to the householder, does not involve noise, can be measured over a specific period, and cannot be biased by the householder cleaning the house before a sample visit ${ }^{4}$

The disadvantages of the method are the potential for disturbance or contamination and the time delay to obtain a measurement. In our study only one dish was lost and there were no overt signs of contamination.

Further evaluation of the technique to quantify the direct relationship between lead loading and blood lead levels is under way in North Lake Macquarie and Broken Hill. Our pilot study has shown that the method provides a valuable indicator of comparative trends in lead exposure over time and between areas.

1. Royal Melbourne Institute of Technology. Reducing Lead Exposure in Australia: Risk Assessment and Analysis of Economic, Social and Environmental Impacts. Canberra: Australian Government Publishing Environmental Impacts. Canberra. Australian Government Publishin Service, 199

2. Rinehart R, Rogers J, Vendetti M. Wipe/vacuum lead in house dust sampling, draft report to US EPA, 1993.

3. Jacobs DE. Guidelines for evaluation and control of lead paint hazards in housing. The National Centre for Lead-Safe Housing for US Department of Housing and Urban Development, 1994

4. Gulson BL, Davis JJ, Mizon KJ, Korsch MJ, Bawden-Smith J. Sources of lead in soil and dust and the use of dust fallout as a sampling medium. Submitted to Sci Total Eviron 1995; 166:245-262.

\section{Update on lead-related activities}

\section{Continued from page 99}

In June 1997, \$4.6 million was received from the NSW Health Department, the NSW Environment Protection Authority and Pasminco Metals-Sulphide for ongoing remediation.

\section{NORTHERN SYDNEY AREA PUBLIC HEALTH UNIT}

Local Government Environmental Health Officers were invited to a regional workshop on roles and responsibilities for lead hazard management conducted by the Lead Reference Centre and the Northern Sydney Area Public Health Unit on 9 December 1997 at Macquarie Hospital, North Ryde. Representatives from local authorities within the area, NSW Environment Protection Authority, WorkCover and Environmental Health Officers from the NSAHS Public Health Unit attended.

Documents distributed included Local Government Lead Management and Guidelines for Environmental Health Officers in managing cases of Elevated Blood Lead Levels. The aim of of the workshop was to provide information about lead hazards and the powers available to deal with lead problems. The outcomes of the day were an awareness of the responsibility of local government in the approval of building applications, procedures to be recommended for building renovations and case investigation protocol. 